\section{Compliance with DOTS among tuberculosis patients under community based DOTS strategy in Palpa District, Nepal}

\author{
Nepal AK, ${ }^{*}$ Shiyalap $K^{2}{ }^{2}$ Sermsri $S,{ }^{2}$ \\ Keiwkarnka B ${ }^{2}$ \\ ${ }^{1}$ Medical Emergency Relief International, Nepal, \\ ${ }^{2}$ ASEAN Institute for Health Development, Mahidol \\ University, Thailand
}

*Correspondence to: Mr. Anant Kumar Nepal, Medical Emergency Relief International, Nepal, email: ananta_nepal@hotmail.com, Tel. No.: (+977)9851042880

\begin{abstract}
INTRODUCTION: Palpa is one of the rural districts of Nepal with high incidence of tuberculosis (TB) where Community Based Directly Observed Treatment Short Course (DOTS) strategy was being trailed to make TB services accessible at community level. In spite of this, it has high defaulter rate; every year more than $5 \%$ patients had defaulted from the treatment and death due to TB was around $6 \%$. The study, therefore, aimed to assess the patients' compliance to the treatment and its associated factors.
\end{abstract}

MATERIALS AND METHODS: A quantitative crosssectional study was carried out using structured interview schedule. All registered TB patients $(n=101)$ who were on treatment were enrolled in the study.

RESULTS: TB patients of younger age group were found to be more compliant to the treatment $(p=0.02)$. Side effect of the drugs was the major reason for the non compliance (36.00\%). More than half of the TB patients had poor knowledge on TB and its treatment. Compliance was found to be significantly associated with knowledge $(p=0.02)$ and perception $(p=0.02)$ of the patients towards TB. Similarly, the study showed positive association between the compliance and service accessibility (distance: $\mathrm{p}=0.00$ ), availability of treatment supervisor $(\mathrm{p}=0.01)$ and health education $(\mathrm{p}=0.02)$.

CONCLUSIONS: Patients' compliance with the TB treatment was found to be associated with their knowledge and perception on $\mathrm{TB}$ and its treatment. Health education and proper counseling was deemed necessary for the patients. Service accessibility along with communication skills training to the providers including community health volunteers can increase compliance rate.

KEY WORDS: Compliance, Community Based DOTS, Tuberculosis

Article submitted 10 July. Reviewed 25 August. Author correction 30 August. Final version accepted 16 September 2012 


\section{INTRODUCTION}

Nepal's commitment to achieve and sustain the Millennium Development Goals (MDGs) by 2015 has pushed policy makers, programme managers and practitioners to take more aggressive tuberculosis (TB) control measures. National TB Programme (NTP) has already expanded Directly Observed Treatment Short Course (DOTS) services throughout the country and has already achieved the targets for case finding and treatment success, and has maintained the achievements over the last several years. However, about $45 \%$ of the total population of the country is estimated to be infected with $\mathrm{TB}$, out of which $60 \%$ belongs to productive age group. Every year, 44,000 people develop active TB, among whom 20,000 have infectious pulmonary TB. Introduction of DOTS has already reduced the number of deaths from TB; however, 5,000-7,000 people still die every year. ${ }^{1}$

Nepal being a mountainous country with uneven population distribution, it is very challenging to make TB services equally accessible. Geographic barriers have made drug distribution and treatment supervision extremely difficult. Importantly, inaccessibility of the services and irregular medication result to poor patients' compliance with the treatment increasing the risk of drug resistance. ${ }^{2}$ DOTS out-reaching services are needed to those hard to reach areas and communities with low socio-economic conditions. ${ }^{3}$ To increase the accessibility of the services, NTP with technical support from Nuffield Center for International Health and Development, United Kingdom has trialled alternative DOTS strategies in few districts of Nepal offering its services at the community level. These included Community Based and Family Based DOTS, where Community Health Volunteers (CHVs) and Family Members provided the medicine under their direct supervision respectively. ${ }^{4}$ As such patients did not need to visit health facility daily for medication. Efforts were made to trace the patients who missed medicine and helped to continue the treatment.

Palpa is one of the rural districts with high incidence of TB. 300-450 TB patients of all forms were notified annually in the district, half of them were new smear positive cases; and every year more than $5 \%$ of the patients were found to have defaulted from the treatment and over $6 \%$ had died due to the TB. ${ }^{3}$ Among the 10 piloted districts, Palpa was the one where Community Based DOTS was implemented in 1999. Female Community Health Volunteers (FCHV), Maternal and Child Health
Health Workers (MCHWs) and Village Health Workers (VHWs), collectively referred to Community Health Volunteers (CHVs) in this study were mobilised as the treatment supervisors. The objective of the study was to assess the compliance of the patients with the treatment under Community based DOTS strategy.

\section{MATERIALS AND METHODS}

Study design and setting: A cross sectional study in Palpa district was conducted applying quantitative method in 2005. Palpa district, with high incidence of TB and high defaulter rate where Community Based DOTS was being trialled, was purposely selected for the study.

Sample size: All tuberculosis patients age $\geq 15$ years old, registered during 6 months (1st July to 31st December 2004) in the DOTS treatment centers of the district were enrolled in the study. Out of 141 registered TB patients, $101 \mathrm{~TB}$ patients were interviewed. All of them were on treatment under Community Based DOTS strategy.

Inclusion criteria: All TB patients aged $\geq 15$ years starting treatment under DOTS between $1^{\text {st }}$ July to $31^{\text {st }}$ December 2004 were enrolled. Patients who had completed 30 doses or more were included. Children were excluded

Research Instruments: Structured interview schedule after pretesting and translated into the local language was used for the study. Patients' general information regarding the treatment was also taken from the TB registers, patient treatment cards and laboratory registers.

Ethical Consideration: The ethical approval was obtained from the approval committee of Mahidol University, Thailand and adhered to university standard operating procedures and guidelines for health research. Informed consent was obtained from each participant and confidentiality in terms of their information and identity was maintained; data were recorded without names.

Validity and Reliability: The interview schedule were pre-tested with 30 TB patients in the same district, who were registered before July 2004 and had been taking treatment under the Community Based DOTS strategy and finalized accordingly. Internal consistency and reliability was ensured in data analysis by obtaining Cronbach's Alpha for perception ( $>0.77$ ) and Kuder Richardson 20 (K-20) for knowledge $(>0.69)$. 
Data analysis: The data was anlysed using Minitab software. Descriptive statistics were used. The patients who had missed the medicine for more than seven consecutive days were taken as non compliant. The patient's knowledge on TB and its treatment were assessed by scoring and categorised into three levels as high, moderate and low according to Bloom classification. Likert scale analysis was done for perception; levels of patient perception were scored as per the Best's group rating criteria; calculate the range of each level, by subtracting the maximum score with minimum score then divided by number of group of measuring level.

Statistical association between the compliance and the patients' socio-demographic characteristics, availability and accessibility of DOTS services, patients' knowledge level and perception was derived; difference between compliance and noncompliance groups with respect to knowledge and perception average score were compared. Chi- square test and Mann-Whitney test were applied ( $\alpha$ $=0.05$ ).

\section{RESULTS}

Among 101 respondents, nearly two-thirds (61.4\%) of TB patients were compliant with TB treatment under Community Based DOTS, whereas more than one-third (38.6\%) of TB patient were noncompliant. Majority (79.5\%) of the non compliant patients had interrupted their treatment during the continuation phase. The major reasons for treatment interruption were side effects of the drugs and feeling of betterment after the treatment. It was also noted that the treatment supervisor had missed to fill the patients' medicine intake in the treatment cards which has also lead to misreporting of the compliance.

\section{Socio demographic factors}

The young age group (15-34 years) had significantly

Table 1. The distribution of patient compliance by socio-demographic characteristics

\begin{tabular}{|c|c|c|c|c|}
\hline \multirow[t]{2}{*}{ Characteristics } & Compliance $(n=62)$ & $\begin{array}{c}\text { Non-compliance } \\
(\mathrm{N}=39)\end{array}$ & \multirow[t]{2}{*}{$\chi 2(\mathrm{df})$} & \multirow[t]{2}{*}{$\mathrm{p}$-value } \\
\hline & n (\%) & $\mathrm{n}(\%)$ & & \\
\hline Age Groups & & & $7.62(2)$ & 0.02 \\
\hline $15-34$ & $26(65.0)$ & $14(35.0)$ & & \\
\hline $35-54$ & $24(75.0)$ & $8(25.0)$ & & \\
\hline$>54$ & $12(41.4)$ & $17(58.6)$ & & \\
\hline Sex & & & $0.05(1)$ & 0.82 \\
\hline Male & $40(60.6)$ & $26(39.4)$ & & \\
\hline Female & $22(62.9)$ & $13(37.1)$ & & \\
\hline Marital Status & & & $0.94(2)$ & 0.62 \\
\hline Single & $9(56.3)$ & $7(43.8)$ & & \\
\hline Married & $48(64.0)$ & $27(36.0)$ & & \\
\hline Others & $5(50.0)$ & $5(50.0)$ & & \\
\hline Occupation & & & $4.13(5)$ & 0.53 \\
\hline Farmer & $25(71.4)$ & $10(28.6)$ & & \\
\hline Govt. employee & $3(75.0)$ & $1(25.0)$ & & \\
\hline Housewife/husband & $12(54.6)$ & $10(45.5)$ & & \\
\hline Labour & $5(50.0)$ & $5(50.0)$ & & \\
\hline Private employee & $6(46.2)$ & $7(53.9)$ & & \\
\hline Other & $11(64.7)$ & $6(35.3)$ & & \\
\hline Education & & & $2.50(3)$ & 0.48 \\
\hline Illiterate & $15(51.7)$ & $14(48.3)$ & & \\
\hline Primary school & $19(67.9)$ & $9(32.1)$ & & \\
\hline Secondary school \& over & $24(66.7)$ & $12(33.3)$ & & \\
\hline Informal education & $4(40.0)$ & $6(60.0)$ & & \\
\hline Family Income (NRs) & & & $7.36(2)$ & 0.02 \\
\hline$\leq 2000$ & $20(50.0)$ & $20(50.0)$ & & \\
\hline $2,001-5,000$ & $27(61.4)$ & $17(38.6)$ & & \\
\hline$\geq 5,000$ & $15(88.2)$ & $2(11.8)$ & & \\
\hline
\end{tabular}


higher percentage of compliance compared to the older age group $(\mathrm{p}=0.02)$ as shown in Table 1 . Similarly, the compliance rate was different among the different levels of family income of the respondents. It was found that patient who had higher family income had higher proportion of compliance with DOTS. The results indicated that there was significant relationship $(\mathrm{p}=0.02)$ between family income and patient compliance (Table 1 ).

\section{Knowledge on TB and its treatment}

Knowledge of the patients on TB and its treatment was assessed. Most of them were aware on symptoms of $\mathrm{TB}$, diagnosis and duration of the treatment. However, over half of the patients were incorrect regarding its transmission, prevention and consequences of irregular and incomplete treatment. Very few of them were aware on side effects of the drugs.

The TB patients who had high knowledge on TB and its treatment had higher proportion of compliance on DOTS than those who had moderate and low knowledge level. The level of patients' knowledge on TB disease and its treatment was significantly associated $(\mathrm{p}=0.02)$ with patient compliance (Table 2).

\section{Perception}

The median score of overall perception for the compliance group was 50 which was higher than the noncompliance group (Median score $=47$ ). There was statistically significant difference $(p=0.02)$ between perception among compliant and noncompliant patients (Table 3).

\section{Availability of service}

Among the patients who met their treatment supervisor in every visit, about $73 \%$ were compliant with the treatment in comparison to those who did not $(47.8 \%)$. Thus non compliance was higher (52.2\%) among those who did not meet their treatment supervisor in every visit (Table 4). A significant relationship $(\mathrm{p}=0.01)$ was found between patients compliance and availability of treatment supervisor.Health education from treatment supervisor in every visit accounted to the increase in patients' compliance with the treatment $(\mathrm{p}=0.02)$. As shown in the Table 4 , about $72.00 \%$ of the compliant patients had received health education from the supervisor compared to those who were not compliant (28.8\%).

\section{Accessibility of service}

No significant difference was found between patient compliance and appropriate time to get the TB drugs. However, the study showed that the travelling time was strongly associated ( $p=0.00)$ with better compliance (Table 5). The proportion of patient compliance was higher $(74.2 \%)$ among TB patient who took less time to travel for treatment than who took more time (more than 30 minutes). The easiest source to get TB information for TB patient was the health workers/volunteers (71.9\%) (Table 5).

\section{DISCUSSION}

The study found that over one-third of TB patient were non-compliant with the treatment even in the Community Based DOTS Strategy. The negligence of the community volunteers to fill up the treatment

Table 2. Comparison of level of knowledge of respondents between compliance and noncompliance group

\begin{tabular}{lcccc}
\hline Variables & $\begin{array}{c}\text { Compliance } \\
(\mathrm{n}=62)\end{array}$ & $\begin{array}{c}\text { Non-compliance } \\
(\mathrm{n}=39)\end{array}$ & $\chi 2(\mathrm{df})$ & $\mathrm{p}$-value \\
\hline & & $\mathrm{N}(\%)$ & $8.16(2)$ & 0.02 \\
High & $32(78.0)$ & $9(22.0)$ & & \\
Moderate & $10(47.6)$ & $11(52.4)$ & & \\
Low & $20(51.3)$ & $19(48.7)$ & & \\
\hline
\end{tabular}

Table 3. Comparison of overall perception of TB patients between compliance and noncompliance groups

\begin{tabular}{|c|c|c|c|c|c|}
\hline Variables & $\begin{array}{l}\text { Compliance } \\
\text { Status }\end{array}$ & Number & $\begin{array}{c}\text { Median (P25th, } \\
\text { P75th) }\end{array}$ & $\mathrm{Z}^{*}$ & $\begin{array}{c}\text { p-value } \\
\text { (2-sided) }\end{array}$ \\
\hline \multirow[t]{3}{*}{ Perception } & & & & 2.36 & 0.02 \\
\hline & Compliance & 62 & $50(46,54.25)$ & & \\
\hline & Noncompliance & 39 & $47(35,52)$ & & \\
\hline
\end{tabular}


Table 4. Relationship between availability of Community Based DOTS services and patient compliance

\begin{tabular}{|c|c|c|c|c|}
\hline \multirow[t]{2}{*}{ Availability factors } & $\begin{array}{c}\text { Compliance } \\
(n=62)\end{array}$ & $\begin{array}{c}\text { Non-compliance } \\
(n=39)\end{array}$ & \multirow[t]{2}{*}{$\chi 2(\mathrm{df})$} & \multirow[t]{2}{*}{$\mathrm{p}$-value } \\
\hline & $\mathrm{n}(\%)$ & N 9\%) & & \\
\hline Available treatment supervisor & & & $6.55(1)$ & 0.01 \\
\hline Yes & $40(72.7)$ & $15(27.3)$ & & \\
\hline No & $22(47.8)$ & $24(52.2)$ & & \\
\hline Available of health education & & & $5.75(1)$ & 0.02 \\
\hline Yes & $42(71.2)$ & $17(28.8)$ & & \\
\hline No & $20(47.6)$ & $22(52.4)$ & & \\
\hline
\end{tabular}

Table 5. Relationship between accessibility of Community Based DOTS services and patient compliance

\begin{tabular}{|c|c|c|c|c|}
\hline \multirow[t]{2}{*}{ Accessibility factors } & $\begin{array}{c}\text { Compliance } \\
(n=62)\end{array}$ & $\begin{array}{c}\text { Non-compliance } \\
(n=39)\end{array}$ & \multirow[t]{2}{*}{$\chi 2(\mathrm{df})$} & \multirow[t]{2}{*}{ p-value } \\
\hline & $\mathrm{n}(\%)$ & $\mathrm{n}(\%)$ & & \\
\hline Appropriate time to get TB drugs & & & $2.46(3)$ & 0.48 \\
\hline All time & $6(46.2)$ & $7(53.8)$ & & \\
\hline Morning & $33(64.7)$ & $18(35.3)$ & & \\
\hline Afternoon & $12(70.6)$ & $5(29.4)$ & & \\
\hline Evening & $11(55.0)$ & $9(45.0)$ & & \\
\hline Average travelling time to get TB drugs & & & $13.28(1)$ & 0.00 \\
\hline$<30$ minutes & $49(74.2)$ & $17(25.8)$ & & \\
\hline 30 and over minutes & $13(37.1)$ & $22(62.9)$ & & \\
\hline Easiest source to get TB information & & & $8.85(3)$ & 0.03 \\
\hline Radio & $10(41.7)$ & $14(58.3)$ & & \\
\hline Health Worker/Volunteer & $46(71.9)$ & $18(28.1)$ & & \\
\hline Other & $6(46.2)$ & $7(53.8)$ & & \\
\hline
\end{tabular}

cards had also lead to the misreporting for the non compliance. So the CHVs needed to be properly trained for recording and reporting as well. Importantly, the proper information regarding the side effects and its management would help to increase the compliance rate. In consistent with other study, the younger age group had higher compliance rate. ${ }^{5}$ Higher literacy and the health consciousness in the age group could be the reasons for higher compliance. The study also revealed that the knowledge on TB and its treatment was associated with patient's compliance with the treatment as with other studies showing the association between the compliance behavior of a patient and his/her knowledge of specific aspect of the disease. ${ }^{6}$ Unlike this, a study (WHO, 2002) ${ }^{7}$ noted no association between knowledge of TB and completion of treatment. Along with its effective result in TB treatment, DOTS strategy also offers the patients opportunity to gain information regarding TB and to maintain good relationship with the providers. The compliance rate was high among TB patient who had positive perception towards disease and treatment. The patients who had an open attitude towards TB were more likely to be compliant. 8,9 The negative views of the patients might make them reluctant to reveal their disease and delayed diagnosis and treatment. In Pakistan, patients often denied their TB diagnosis and rejected the treatment due to fear of social isolation. ${ }^{10}$ Moreover, the positive perception and attitude towards $\mathrm{TB}$ and its treatment may also contribute to acquire knowledge and likely to receive more of the information provided to them. Various misconception and stigma were noted in the study like TB affects in marriage arrangement. Because of the fear of difficulty in finding partner for marriage, parents may be reluctant to send girls of marriageable age for treatment. ${ }^{6}$

Presence of treatment supervisors and availability health education from them were also found to be associated with compliance of the patients with the treatment. The patients who meet treatment supervisor regularly might feel comfortable to collect the drugs and would be encouraged to regular treatment. Improved health education for TB patients help to increase the treatment compliance. ${ }^{11}$ Compliance with the treatment is enhanced if patients receive adequate education. ${ }^{12}$ 
Training of health workers and community volunteers on communication skills may help them to provide adequate information and to motivate the patients to complete their treatment. Unlike the study by Liem LT, 199913 in which TV and Radio are the most popular and easiest sources of information for TB patient, the study found that the health workers/volunteers are the easiest and best source of information on TB for the patients.

Studies have shown that distance and inconvenient consulting hours hinder the patients' compliance with the treatment. ${ }^{14,15}$ The study also showed that the compliance was associated with the long travelling time of patients. Therefore increasing the service accessibility also would reduce the non compliance and help the patient in complete and regular treatment.

\section{CONCLUSIONS}

Though, NTP Nepal established an alternative strategy for easy access to TB services at community level, patient compliance is still affected by various factors. Health education on TB and its treatment is most crucial, which increase the compliance rate. Therefore, the patients along with the family members must to be provided with adequate information. The orientation and interaction activities should be carried out involving health workers and volunteers together with TB patients and community people to minimise social stigma and help TB patients to get support in completing treatment. There is need to properly train and reinforce Community Health Volunteers in order to closely and directly support TB patient along with reminding TB patient frequently for regular treatment. Further attention of easy accessible and available services is required to improve the compliance of TB treatment. The performance of CHVs as treatment supervisor in TB programme should be assessed as they are providing volunteers service under Community Based DOTS strategy.

\section{ACKNOWLEDGEMENTS}

Sincere gratitude to all staff of DOTS Centers, Palpa, and special thanks to Fr. Amulya Nath Sharma (Nepal) and Fr. Cardinal M. Michai Kitbunchu (Thailand) for partial financial support.

CONFLICT OF INTEREST: None to declare.

FINANCIAL INTEREST: None to declare.

\section{REFERENCES}

1. Ministry of Health and Population, Nepal. Available from: (http://www_moh_gov_np).htm accessed on 6th May 2009

2. World Health Organization. World TB day Kit 1998 [online]. Available from: htt://www/who.int/-pr1999/en/pr99-16.html accessedMay 2009.

3. National Tuberculosis Control Program. Nepal National Tuberculosis Center; Annual Report 2002-2003. Kathmandu, Nepal: National Tuberculosis Center, 2003.

4. Newell JN, Baral SC, Pande SB, Bam DS, Malla P. Family-member DOTS and community DOTS for tuberculosis control in Nepal: cluster-randomised controlled trial. Lancet 2006;367:903-909

5. Bam TS, Gunneberg C, Chamroonsawasdi K et al. Factors affecting patient adherence to DOTS in urban Kathmandu, Nepal. Int J Tuberc Lung Dis 2006;10:270276.

6. Barnhoorn F, Adriaanse H. In search of factors responsible for noncompliance among tuberculosis patients in Wardha district, India. Soc Sci Med 1992;34:292-306.

7. World Health Organization. TB notes. Geneva: The Organization; 2002.

8. Lee RP, Chiou YF. The Compliance behavior of patients with pulmonary Tuberculosis in Hualien, Taiwan. Tzu Chi Med J 1997;9:219-227.

9. Demissie M, Getahun H, Lindtjrn B. Community tuberculosis through "TB clubs" in rural North Ethiopia. Soc Sci Med 2003;56:2009-2018

10. Liefooghe R, Michiels N., Habib S., Moran MB., Muynck DA. Perception and social consequences of tuberculosis: a focus group study of tuberculosis patients in Sialkot, Pakistan. Social Science and Medicine 1995;41:1685-1692

11. O’Boyle SJ, Power JJ, Ibrahim MY, Watson JP. Factors affecting patient compliance with anti tuberculosis chemotherapy using directly observed treatment short course strategy (DOTS). Int J Tuberc Lung Dis 2002;6:307-312.

12. Morisky D, Malotte C, Choi P. A patient education programme to improve adherence rates with antituberculosis drug regimens. Health Educ Q 1990;17:253-267.

13. Liem LT. Patient's delay in seeking treatment for pulmonary tuberculosis among adult population in Longan province, Vietnam [M.P.H.M. Thesis in Primary Health Care Management] Nakhonpathom: Faculty of Graduate Studies, , Mahidol University; 1999.

14. Toman K. Tuberculosis case finding and chemotherapy: Questions and Answer. Geneva: WHO, 1979.

15. Rouillon A. Problems in organizing effective ambulatory treatment of tuberculosis patients. Bull Union Int Tuber 1972;47:68-83.

Citing this article

Nepal AK, Shiyalap K, Sermsri S, Keiwkarnka B. Compliance with DOTS among Tuberculosis patients under community based DOTS strategy in Palpa District, Nepal. Int J Infect Microbiol 2012;1(1):14-19. 